\title{
Keyword Index Volume 19 (2011)
}

$\begin{array}{lrlr}\mu \text {-CT } & 29 & \text { diagnostic imaging } & 373 \\
& & \text { differential equation } & 217 \\
\text { 3D CT measurement } & 185 & \text { distraction osteogenesis } & 173 \\
& & \text { Doppler measurement } & 205 \\
\text { accelerometer } & 319 & & \\
\text { accuracy } & 185 & \text { early genetic testing } & 349 \\
\text { acetabular cup orientation } & 185 & \text { effective orifice area and performance index } & 205 \\
\text { adaptive segmentation } & 319 & \text { Ehrlich tumor } & 455 \\
\text { adaptive technology } & 349 & \text { electromagnetic field } & 435 \\
\text { ADL recognition } & 37 & \text { endoscopic image classification } & 79 \\
\text { age } & 195 & \text { enterprise information integration } & 115 \\
\text { anterior knee pain } & 91 & \text { evidential ontology network of activity } & 37 \\
\text { arthrodesis } & 195 & \text { extremely low frequency } & 455 \\
& & & \\
\text { Bernoulli } & 205 & \text { fellow evaluation } & 79 \\
\text { best practices } & 423 & \text { FGF-2 (fibroblast growth factor) } & 469 \\
\text { binary sensors } & 37 & \text { Finite Element Analysis } & 217 \\
\text { bioreactor } & 55 & \text { fusion } & 195 \\
\text { bone fracture } & 261 & & \\
\text { bone healing } & 173 & \text { GAP analysis } & 115 \\
\text { breast cancer } & 349 & \text { GSM } & 435 \\
& & \text { GVF snakes } & 401 \\
\text { callus } & 261 & & \\
\text { canine } & 271 & \text { hand hygiene } & 319 \\
\text { capacity planning } & 247 & \text { haptic interface } & 483 \\
\text { cell culture } & 223 & \text { hBMSC } & 223 \\
\text { cell proliferation } & 469 & \text { health insurance portability and accountability } \\
\text { cementless } & 29 & \text { act (HIPPA) } & 423 \\
\text { centers for medicare and medicaid services } & & \text { health service } & 247 \\
\quad \text { CMS) } & 423 & \text { health technology management } & 445 \\
\text { clinical engineering } & 445 & \text { heart valve } & 205 \\
\text { coagulation } & 109 & \text { hemostasis } & 109 \\
\text { complication } & 195 & \text { heparin } & 109 \\
\text { consolidation } & 173 & \text { high frequency ventilation } \\
\text { database analysis } & & \text { hip resurfacing arthroplasty } & 307 \\
\text { dementia } & 445 & \text { hospital payment } & 247 \\
& 233 & \text { hospital planning } & \\
& & & \\
& & & \end{array}$




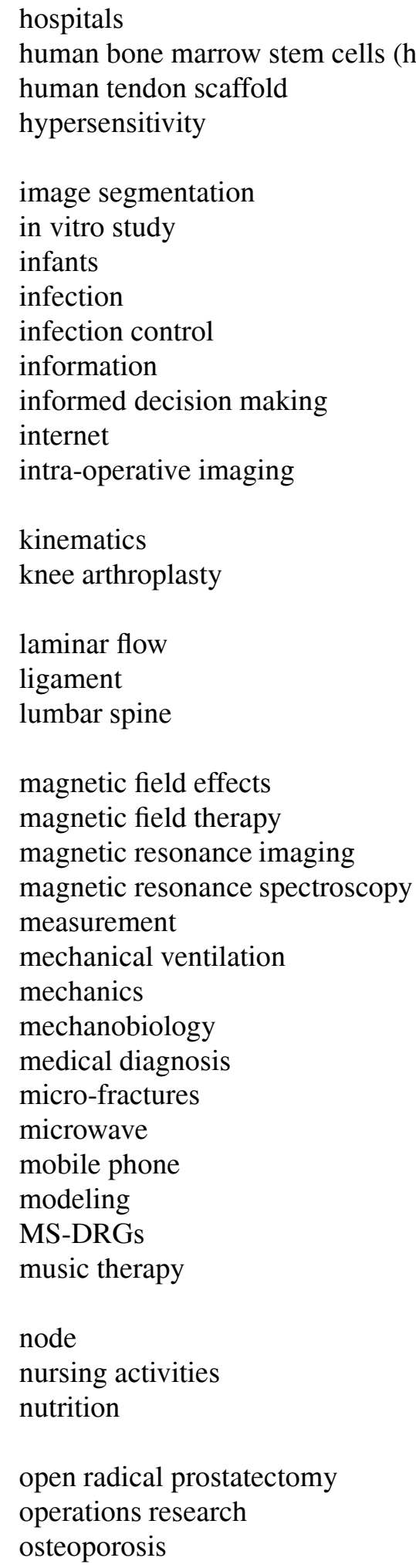

247 patient flow

phantom model

$$
\text { quality }
$$

robot

smart homes pharmacy process flow

Real-time location systems 
support vector machines

surgery

synchronized mechanical ventilation

system dynamics

system simulation modeling

telemetric in vivo measurement

tendon

three-dimensional imaging

tibia plateau fracture

Tissue dielectrics

tissue engineering

tissue formation

total knee arthroplasty

training simulator

transition points

translational medicine
79 treatment

195 T-snakes

401

307 turbulent flow

205

247 two-stage revision

167

1

ultrasound

261

173 upper endoscopy

223, 469 usability

71

71 vascular surgery

109

455 video game

233

223, 469 virtual reality

483

55 vital signs

435

167 vitality

103

29

319

349 Wiimote 